Revista Energia na Agricultura

ISSN 1808-8759

\title{
ANÁLISE ENERGÉTICA DO PROCESSO EXPERIMENTAL DE PRODUÇÃO DE BIODIESEL
} A PARTIR DE ÓLEO DE FRANGO ${ }^{1}$

RICARDO PACHECO BONOMETO ${ }^{2}$, ANDRÉ LUIZ JUSTI ${ }^{3}$, ALISSON TEIXEIRA BUCHI ${ }^{4} \&$ JOSÉ $^{2}$ ROBERTO SAGLIETTI ${ }^{5}$

RESUMO: Existe uma grande preocupação mundial com o esgotamento e o alto custo de exploração das reservas de combustíveis fósseis e, portanto, mais do que nunca, é necessário o aprofundamento do estudo e aproveitamento de fontes alternativas que possam ser utilizadas com eficiência energética, preços adequados e com baixo impacto ambiental. O Brasil se destaca na utilização das fontes alternativas de energia com o uso do etanol e, nos últimos anos vem incentivando a ampliação de sua matriz energética a partir das fontes alternativas, na qual o biodiesel passa a ter uma importância estratégica dentro da área de agronegócios. O biodiesel é um combustível que pode substituir o diesel, que é um derivado do petróleo; é um éster produzido na reação de transesterificação de óleos vegetais, goduras animais que, na presença de um álcool e um catalisador, são convertidos em ácidos graxos, resultando em ésteres com glicerol como subproduto. O objetivo deste trabalho foi analisar energeticamente o processo de produção de biodiesel a partir do óleo dos resíduos descartados na produção de frango. Para a estimativa deste balanço de energia quantificou-se o poder calorífico de alguns dispêndios energéticos através do método da bomba calorimétrica. A relação entre as entradas e saídas de energia ficou em torno de 0.97 ; significando, numa primeira avaliação, que os procedimentos adotados devem ser melhorados para que o processo torne-se energética e economicamente viável.

Palavras-chave: Análise energética, óleo de frango, poder calorífico.

\footnotetext{
${ }^{1}$ Parte da dissertação de mestrado do primeiro autor intitulada: Análise energética do processo experimental de produção de biodiesel a partir de óleo de frango.

${ }^{2}$ Aluno do Programa de Pós-Graduação - Energia na Agricultura, FCA/UNESP - Botucatu/SP .Rua Irmã Dulce, 311, Cep:85806-746. Cascavel/Pr, Brasil, e-mail: rpbonometo@yahoo.com.br

${ }^{3}$ Aluno do Programa de Pós-Graduação - Irrigação e Drenagem, FCA/UNESP - Botucatu/SP. Fazenda Experimental Lageado - Cep: 18603-970 - Botucatu, SP. Caixa Postal: 237, Brasil, e-mail: aljusti@fca.unesp.br

${ }^{4}$ Aluno do Programa de Pós-Graduação - CEVAP - Centro de Estudos de Venenos e Animais Peçonhentos, U-

NESP/Botucatu, Brasil. Fazenda Experimental Lageado - Cep: 18603-970 - Botucatu, SP. Caixa Postal: 237, Brasil, e-mail: atbuchi@yahoo.com.br

${ }^{5}$ Orientador e docente do Departamento de Física e Biofísica, FCA/UNESP, Botucatu/SP. Distrito de Rubião Júnior S/N - Cep: 18618-000 -Botucatu, SP. Caixa Postal: 510, Brasil, e-mail: jroberto@ibb.unesp.br
} 


\section{ENERGETIC ANALYSIS OF EXPERIMENTAL PROCESS IN BIODIESEL PRODUCTION FROM CHICKEN OIL}

SUMMARY: There is a great global concern about the depletion and the high cost of fossil fuel reserves exploitation, more than ever, it is necessary to make a profound study and take advantage of alternative sources that can be used as energy efficiency with an appropriate pricing and low environmental impact. Brazil, which has highlighted using alternative energy sources as the use of ethanol and, in recent years, has been encouraging the expansion of its energy matrix in which the biodiesel will have a strategic importance within the agrobusiness area. Biodiesel is a fuel that can replace the diesel, which is a petroleum derivative. It is an ester, produced in the transesterification reaction of vegetable oils and animal greases, in an alcohol with an additional catalyst, are converted into fatty acids and result in esters with glycerol as sub products. The objective of this study was to estimate the final energy balance for the process biodiesel production from oil chicken waste. The energy balance estimation was quantified in calorific value according to the energy expenditure by calorimetric bomb method. The relationship between input and output of energy was around 0.97. In a first evaluation, the procedures adopted should be improved enough, so the process can become energetic and economically viable.

Keywords: Energy analysis, oil of chicken, calorific value

\section{INTRODUÇÃO}

Devido à grande preocupação com o esgotamento das reservas de petróleo e a manutenção do equilíbrio ambiental, muito se tem investido nas pesquisas de combustíveis alternativos, procurando tornálos economicamente viável, sendo um deles, o biodiesel.

O biodiesel é um combustível que possui um processo de combustão com menos emissão de gases poluentes e que pode ser obtido a partir de fontes renováveis, tais como óleos vegetais e gorduras animais. Um dos processos de obtenção do biodiesel é a transesterificação, processo que consiste na reação de um triglicerídeo com um álcool de cadeia curta, metanol ou etanol, e um catalisador. A reação gera o biodiesel e, como subproduto, a glicerina. Este combustível surge como uma alternativa à dependência do diesel de petróleo. 
As principais fontes para a produção do biodiesel incluem uma grande variedade de oleaginosas, gorduras de origem animal e óleos residuais, entretanto, poucos são os estudos de avaliação energética do processo que envolve a produção de biodiesel.

Conforme Parente (2003), define-se biodiesel como um combustível renovável, biodegradável e ambientalmente correto, sucedâneo ao óleo diesel mineral, constituído de uma mistura de ésteres metílicos ou etílicos de ácidos graxos, obtidos da reação de transesterificação de qualquer triglicerídeo com um álcool de cadeia curta, metanol ou etanol, respectivamente.

Para Costa (2006), o biodiesel é um éster produzido na reação de transesterificação de óleos vegetais e ou gorduras animais em conjunto com um álcool (metanol ou etanol) e na presença de um catalisador, convertidos em ácidos graxos e, finalmente, a ésteres, com o glicerol (glicerina) como subproduto.

Segundo Lopes (2006) o uso do biodiesel nos automóveis a diesel reduz a emissão de fumaça, monóxido de carbono, óxidos de enxofre e hidrocarbonetos aromáticos. É um combustível renovável, não tóxico e composto de ésteres metílicos ou etílicos derivados de triglicerídeos (óleos vegetais ou gordura animal).

Os trabalhos com o biodiesel no Brasil não tiveram muito avanço até o ano de 2004 quando voltou a ter destaque no cenário dos combustíveis alternativos, com o lançamento do Programa Nacional de Produção e Uso do Biodiesel (PNPB), patrocinado pelo governo federal.

$\mathrm{O}$ ressurgimento do biodiesel como fonte de energia alternativa ocasionou a necessidade de pesquisas voltadas ao seu melhor desenvolvimento e aplicação, sendo a análise energética uma das mais importantes para torná-lo economicamente viável.

A análise energética quantifica a energia diretamente consumida e a energia indiretamente utilizada, podendo assim, contribuir na obtenção de indicadores de viabilidade técnico-econômica e ambiental, como também na comparação de diferentes processos e matérias-primas na obtenção do biodiesel. Uma das maneiras de se obter a análise energética é a partir do poder calorífico dos componentes e dispêndios energéticos que envolvem o sistema analisado.

O poder calorífico superior (PCS), é aquele em que a combustão se efetua a volume constante e no qual a água formada durante a combustão é condensada e o calor derivado desta condensação é recuperado (BRIANE; DOAT, 1985)

Para Rocha (2007), a utilização de combustíveis derivados da biomassa, como o biodiesel. vem sendo apresentada como uma alternativa energética menos impactante que o seu concorrente de origem fóssil, o diesel.

O Brasil tem todas as condições para se tornar um grande produtor de biodiesel. O país tem potencial incomparável para gerar biomassa com fim energético (LIMA, 2004), sem que isso prejudique a produção de alimentos, dada a grande área agricultável disponível no país. 
Neste trabalho objetivou-se analisar o balanço de energia do processo de produção do biodiesel a partir de óleo de frango. O óleo de frango, tido como matéria residual nos frigoríficos, é opção para a produção de biodiesel, considerando a alta produção e baixo custo desta matéria-prima.

O uso de óleo, proveniente das aves, na produção de biodiesel apresenta também uma importante função na questão ambiental, pois, a utilização destas matérias-primas na produção do combustível minimiza os impactos negativos ao meio ambiente. Esta estimava fez-se pela subtração das energias de saída pelas energias de entrada.

\section{MATERIAL E MÉTODOS}

Este trabalho foi realizado no Centro de Desenvolvimento e Difusão de Tecnologias (CEDETEC), junto ao departamento de Agronomia da Faculdade Assis Gurgacz (FAG), no laboratório experimental de Biodiesel, localizado na cidade de Cascavel na região Oeste do Paraná.

Analisou-se energeticamente o processo de obtenção do biodiesel a partir de uma planta experimental, onde, a rota tecnológica de produção é a rota de transesterificação metílica.

A matéria-prima em estudo foi o óleo de frango, de grande quantidade na região Oeste do Paraná. A planta possui capacidade instalada de 900 litros/dia,

Foram coletadas amostras, denominadas "inputs" e "outputs", ou seja, "entradas" e "saídas", através das quais se determinou o poder calorífico de alguns elementos para a confecção do balanço energético do biodiesel.

As amostras coletadas foram distintas durante o processo de produção por batelada, na qual ocorre o processo de transesterificação. Todo o processo de batelada se dá em torno de 9 horas.

Verificaram-se as "entradas" e "saídas" energéticas, onde, as entradas energéticas foram determinadas sendo: energia elétrica, lenha, óleo de frango, metanol e o catalisador hidróxido de sódio. As saídas: glicerina a partir de óleo de frango, biodiesel de óelo de frango.

\subsection{Energia Elétrica}

A energia elétrica foi quantificada a partir da análise dos gastos durante uma batelada. A planta experimental apresentava 12 motores que operavam em momentos distintos durante o processo de batelada. A quantificação dos motores deu-se multiplicando a potência nominal pelo tempo de operação de cada motor. 
O coeficiente energético para eletricidade foi considerado o mesmo como de origem hídrica igual a 3,6 MJ.kWh ${ }^{-1}$ (NOGUEIRA, 1987).

A quantidade de energia gasta no processo foi de $18,83 \mathrm{kWh}$. Estes valores se deram em função do tempo de utilização de cada motor no processo.

\subsection{Lenha}

Foram adquiridas amostras da lenha utilizada na caldeira durante o processo de produção do biodiesel. A espécie analisada foi a Mimosa scabrella, Bracatinga, e no processo de produção utilizou-se cerca de $250 \mathrm{~kg}$ de lenha com umidade média de $20 \%$. Onde, para os cálculos finais retiraram-se os $20 \%$ de umidade resultando $200 \mathrm{~kg}$ de lenha seca.

A determinação desta entrada energética foi através do poder calorífico em laboratório a partir do calorímetro.

Para a determinação do poder calorífico foi feito uma pastilha de um 1,0g. Esta pastilha foi seca em estufa num período de 24 horas, a $105{ }^{\circ} \mathrm{C}$ até a estabilidade de sua massa a $0 \%$ de umidade e depois deste processo fez-se a queima na bomba calorimétrica.

O poder calorífico superior médio encontrado foi de $19,88 \mathrm{MJ} \cdot \mathrm{kg}^{-1}$

\subsection{Metanol e óleo de frango}

A matéria-prima em análise foi o óleo de frango. Para a produção do biodiesel utilizou-se 490 litros de óleo, o que corresponde a uma massa efetiva de 445,9 kg. A densidade do óleo de frango considerada foi de $0,91 \mathrm{~g} \cdot \mathrm{cm}^{-3}$ (BELLAVER, 2004).

Para a determinação do poder calorífico, inicialmente tentou-se a queima do óleo em seu estado natural, mas não houve a combustão completa. Fez-se então, uma mistura do óleo de frango com metanol (álcool metílico P.A. - teor: 99,5\%) de modo que a massa da mistura ficasse em torno de 1,0 g e assim pôde-se determinar o PCS da amostra. Como no processo metílico o óleo de frango é homogeneizado com o metanol, parece razoável que a obtenção de um PCS que avalie os dois componentes seja usada, desde que as massas sejam somadas, o que foi feito neste caso. O processo de queima no calorímetro realizou-se em 12 repetições para ambas as amostras.

Para a estimativa energética utilizou-se $77,58 \mathrm{~kg}$ de metanol. O metanol é o álcool usado predominantemente em todo o mundo na produção de biodiesel. Foram usados 98 litros de metanol cuja função 
é fazer a transesterificação do óleo de frango. A densidade do metanol considerada foi de $0,79 \mathrm{~g} \cdot \mathrm{mL}^{-1}$, segundo Geris (2007).

Utilizou-se para mistura, metanol mais óleo de frango e o valor do PCS encontrado foi de 30,07 MJ.kg-1 ${ }^{-1}$ maior que o do metanol e menor do que os óleos vegetais, o que parece ser um valor coerente com os indicadores separados.

\subsection{Catalisador}

Para a produção de biodiesel utilizam-se catalisadores para acelerar o processo de transesterificação. Os catalisadores utilizados podem ser o hidróxido de sódio $(\mathrm{NaOH})$ ou o hidróxido de potássio $(\mathrm{KOH})$. Para a batelada foi utilizado o hidróxido de sódio.

Na produção do biodiesel de óleo de frango utilizou-se $2,45 \mathrm{~g}$ de hidróxido de sódio $(\mathrm{NaOH})$. Seu coeficiente energético utilizado correspondeu a $44.45 \mathrm{~kJ}^{\mathrm{mol}}{ }^{-1}$ (LIDE, 1991).

\subsection{Glicerina}

A glicerina é um subproduto do biodiesel e é uma matéria-prima de alto valor agregado que pode ser empregada em uma ampla variedade de produtos, tais como, químicos, cosméticos, alimentícios e farmacêuticos.

A glicerina resultante do processo de transesterificação é considerada glicerina bruta. A densidade da glicerina, segundo Santos (2007) é de 1,26 g. $\mathrm{mL}^{-1}$.

Para determinar o poder calorífico tomou-se aproximadamente $1,0 \mathrm{~g}$ de cada amostra. O processo de queima da amostra no calorímetro foi realizado em 12 repetições para cada tipo de glicerina. Em algumas amostras foi necessário descontar o peso do cadinho, 8,29g, isto quando a queima não era total, ou seja, após a queima no calorímetro sobravam resíduos da amostra no cadinho.

A quantidade de glicerina usada foi e 46,8 litros e a massa para estimativa foi 58,96 g. O poder calorífico superior médio foi de $32,81 \mathrm{MJ} \cdot \mathrm{kg}^{-1}$.

\subsection{Biodiesel}

O biodiesel é, junto com a glicerina, a principal saída energética. A metodologia para identificação do coeficiente energético foi por meio da determinação do poder calorífico. 
Para a determinação do poder calorífico fez-se a queima no calorímetro de aproximadamente $0,5 \mathrm{~g}$ de cada amostra. Foram realizadas 12 repetições para cada amostra. A determinação da massa é feita em função da densidade do óleo de frango que é de $0,87 \mathrm{~g} \cdot \mathrm{mL}^{-1}$ (SECCO etal. 2008).

A massa encontrada para os cálculos de estimativa de balanço de energia foi 407,2 kg. Sendo que, dos 490 litros iniciais de óleo de frango obtivemos 468 litros de biodiesel.

Para o biodiesel de óleo de frango, sendo este uma das saídas energéticas, determinou-se poder calorífico médio de 42,53 MJ.kg ${ }^{-1}$.

\subsection{Poder calorífico}

A determinação do poder calorífico das amostras foi realizada através do método da Bomba Calorimétrica.

Para a determinação do poder calorífico superior (PCS), a amostra de determinada substância foi pesada e acomodada num cadinho e ambos foram colocados no reator do calorímetro, que é a bomba calorimétrica. $\mathrm{O}$ sistema foi pressurizado com oxigênio, esperando-se a estabilização da temperatura da água; na seqüência, efetuou-se a queima.

A massa de água (Ma) utilizada no Calorímetro foi de $2.500 \mathrm{~g}$ e o valor da constante do Calorímetro (K) foi previamente determinado na calibração do Calorímetro, sendo de $480 \mathrm{~g}$.

O poder calorífico superior (PCS) foi determinado pela seguinte relação:

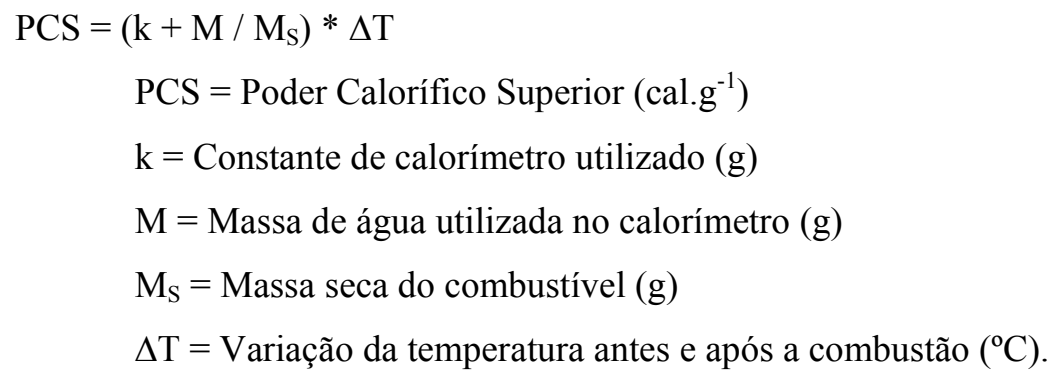

\subsection{Análise de energia}

O balanço energético pode fornecer informações importantes para avaliar as conseqüências energéticas do emprego de novas fontes de energia e de políticas energéticas, além de identificar áreas onde as aplicações das técnicas de conservação de energia são mais úteis (LOPES, 2006). 
Para a realização da estimativa do balanço de energia fez-se a relação produção/consumo entre as saídas e as entradas energéticas identificando-se os valores dos dispêndios energéticos utilizados na produção do biodiesel. Para se obter a produção energética final multiplicou-se a massa de cada insumo por seu índice energético e assim, conseguiu-se determinar a relação produção/consumo. Os resultados foram apresentados em Megajoules (MJ).

\section{RESULTADOS E DISCUSSÃO}

O balanço de energia pode ser caracterizado pela quantidade de energia que entra no processo subtraído da energia que sai. Os resultados são apresentados e discutidos para os dispêndios energéticos e para a relação produção/consumo entre as entradas e saídas de energias.

O balanço de energia indica um parâmetro de viabilidade técnica do processo para a produção de biodiesel de óleo de frango e neste estudo ele apontou valor negativo, sendo que, isto pode ser revisto para melhorar o processo industrial.

Por este motivo, embora o intuito inicial desta pesquisa fosse o de realizar um balanço completo, sugere-se que este estudo seja visto como uma análise de energia num processo experimental no qual parâmetros comumente usados para um balanço formal, foram avaliados dentro de certas limitações tanto no processo produtivo como na parte laboratorial.

As Tabelas indicam, o quantitativo de insumo utilizado na produção de biodiesel, potencial energético e a produção energética para as entradas e saídas de energia.

Tabela 1 - Quantitativo para o balanço de energia, entradas de energia.

\begin{tabular}{|c|c|c|c|c|c|}
\hline \multicolumn{6}{|l|}{ Entradas de Energia } \\
\hline & Unidades & Insumo & $\begin{array}{l}\text { Potencial Energé- } \\
\text { tico }\end{array}$ & $\begin{array}{l}\text { Produção } \\
\text { (MJ) }\end{array}$ & Energética \\
\hline Eletricidade & $\mathrm{kWh}$ & 18,83 & 3,6 & 67,8 & \\
\hline Lenha (massa seca) & $\mathrm{kg}$ & 200 & 19,88 & 3.976 & \\
\hline Catalisador $(\mathrm{NaOH})$ & $\mathrm{kg}$ & 2,45 & 44,45 & 2,72 & \\
\hline \multicolumn{6}{|l|}{ Óleo de frango $+\mathrm{Me}-$} \\
\hline tanol & $\mathrm{kg}$ & 523,48 & 30,07 & $15.741,04$ & \\
\hline Total & & & & $19.787,56$ & \\
\hline
\end{tabular}


Tabela 2 - Quantitativo para o balanço de energia, saídas de energia.

\begin{tabular}{llll}
\hline Saídas de Energia & & & \\
\hline & $\begin{array}{l}\text { Insumo } \\
(\mathbf{k g})\end{array}$ & $\begin{array}{l}\text { Potencial } \\
\mathbf{( M J . k g - 1 )}\end{array}$ & $\begin{array}{l}\text { Energético } \\
\text { Produção Energética } \\
\mathbf{( M J )}\end{array}$ \\
\hline $\begin{array}{l}\text { Biodiesel óleo de frango } \\
\text { Glicerina óleo de frango }+ \\
\text { Metanol }\end{array}$ & 507,2 & 42,53 & $17.316,51$ \\
\hline Total & 58,96 & 32,81 & $1.934,74$ \\
\hline
\end{tabular}

O biodiesel apresentou produção energética de 17.316,51 MJ, para uma massa de 407,2 kg, valor não desprezível, principalmente por estar dentro do esperado e isto aponta que o caminho a ser percorrido é correto, embora necessite de alterações inerentes nos novos processos.

$\mathrm{O}$ resultado final apontou para um processo com deficiência energética no qual se coloca mais energia do que aquela que foi obtida, na razão de 0.97 , o que em princípio indica uma alternativa inviável.

\section{CONCLUSÕES}

O valor da análise energética de 0,97 revela um processo com grande potencial e que não deve ser descartado. Indicando que, o uso de óleos obtidos a partir de resíduos de produção animal, principalmente os de frango, podem ser vistos como uma solução ambiental ainda que o produto obtido seja energeticamente deficitário.

\section{AGRADECIMENTO}

A equipe do CEDETEC/FAG - Cascavel, e equipe do Departamento de Física e Biofísica/UNESP - Botucatu, pelas sugestões e auxílio no desenvolvimento deste trabalho. 


\section{REFERÊNCIAS}

BELLAVER, C.; ZANOTTO, D. L. Parâmetros de qualidade em gorduras e subprodutos protéicos de origem animal. In: CONFERÊNCIA APINCO, 2004, Santos, SP, 2004.

BRIANE, D.; DOAT, J. Guide technique de la carbonisation: la fabrication du charbon de bois. Aix-enProvence: ÉDISUD, 1985.

COSTA, R. E.; etal. Balanço energético preliminar da produção do biodiesel de óleo de palma para condições do Brasil e da Colômbia. Campinas, Agrener, 2006.

GERIS, R. SANTOS, N. A. C.; etal. Biodiesel de soja: reação de transesterificação para aulas práticas de química orgânica. Química Nova, v.30, n 5, p. 1369-1373, 2007.

LIDE, D. R. CRC handbook of chemistry and physics. 71th ed. Boston: CRC, 1991.

LIMA, P. C. R. O biodiesel e a inclusão social. Brasília, DF. Consultoria Legislativa da Câmara dos Deputados, 2004.

LOPES, E. M. Análise energética e da viabilidade técnica da produção de biodiesel a partir de sebo bovino. 2006. 100f. Dissertação (Mestrado em Ciências da Engenharia da Energia) Universidade Federal de Itajubá, UNIFEI, Itajubá, 2006.

NOGUEIRA, L. A. H. Análise da utilização de energia na produção de álcool de cana de açúcar. 1987. Tese (Doutorado) Universidade Estadual de Campinas, Campinas, 1987.

PARENTE, E. J. S. Biodiesel: uma aventura tecnológica num país engraçado. Fortaleza: Tecbio, 2003.68p.

ROCHA, T. B.; ALMEIDA NETO, J. A. Análise energética na produção do biodiesel de mamona: estudo comparativo entre as rotas catalíticas homogênea e heterogênea. Cilca, 2007. 
SANTOS, V.A. Decantação cntínua da mistura biodiesel-glicerina1: modelagem dinâmica. 2007.

Disponível em:

<www.biodiesel.gov.br/docs/congresso2007/producao/18.pdf>. Acessado em 10 de maio de 2009.

SECCO, W. Produção de biodiesel a partir da gordura de frango. XVI ENCONTRO DE QUÍMICA DA REGIÃO SUL. 2008. Disponível em:

<www.furb.br/temp_sbqsul/_app/_FILE_RESUMO.../865.pdf>. Acessado em 10 de maio de 2009. 